This item was submitted to Loughborough's Research Repository by the author.

Items in Figshare are protected by copyright, with all rights reserved, unless otherwise indicated.

\title{
Implications of environmental conditions for health status and biomechanics of freshwater macrophytes in hydraulic laboratories
}

\section{PLEASE CITE THE PUBLISHED VERSION}

https://doi.org/10.1080/24705357.2019.1669496

\section{PUBLISHER}

Informa UK Limited

\section{VERSION}

AM (Accepted Manuscript)

\section{PUBLISHER STATEMENT}

This is an Accepted Manuscript of an article published by Taylor \& Francis in Journal of Ecohydraulics on 11 Nov 2019, available online: https://doi.org/10.1080/24705357.2019.1669496

\section{LICENCE}

CC BY-NC-ND 4.0

\section{REPOSITORY RECORD}

Vettori, Davide, and Stephen Rice. 2019. "Implications of Environmental Conditions for Health Status and Biomechanics of Freshwater Macrophytes in Hydraulic Laboratories". Loughborough University. https://hdl.handle.net/2134/14216129.v1. 
Implications of environmental conditions for health status and biomechanics of freshwater macrophytes in hydraulic laboratories

Davide Vettori ${ }^{1}$, Stephen P. Rice ${ }^{2}$

${ }^{1}$ Geography and Environment, School of Social Sciences, Loughborough University,

Loughborough, LE11 3TU UK. Email: d.vettori@lboro.ac.uk (Corresponding author)

${ }^{2}$ School of Social Sciences, Loughborough University, Loughborough, LE11 3TU UK. Email:

s.rice@lboro.ac.uk 


\title{
Implications of environmental conditions for health status and biomechanics of freshwater macrophytes in hydraulic laboratories
}

\begin{abstract}
Submerged freshwater macrophytes are frequently used in hydraulic laboratories to study flow-plant interactions and the role of plants in aquatic ecosystems, but environmental conditions in flume facilities are often suboptimal for plants and can cause plant stress. Physiological responses of plants under stress can trigger modifications in plant biomechanics, which may affect plant-flow interactions and compromise experimental results. In the extreme, dead plants cannot be expected to reveal how live plants interact with flowing water, but stressed plants that are not visibly unhealthy may also affect experimental results. The present work aims to assess if and how environmental conditions typical of flume facilities can impact plant health status and induce variations in plant biomechanics. Using chlorophyll fluorescence analysis, a standard method for assessing plant health, we found that freshwater macrophytes can be significantly stressed under conditions typically found in hydraulic laboratories. Even though the abiotic factors investigated affected different species in different ways, exposure to tap water and low irradiance were the most stressful conditions for freshwater macrophytes. Biomechanical properties with a primary role in flow-plant physical interactions (e.g. flexural rigidity) changed significantly as a result of exposure to stressful conditions. In general, plant stress was associated with a reduction in flexural rigidity at the top of plant stems, suggesting a potential effect on plant hydrodynamics when leaves and petioles are considered. The maximum quantum yield of photosystem II, used as proxy of plant health status, was positively correlated with flexural rigidity of plant stems.
\end{abstract}

Keywords: Freshwater macrophytes, Chlorophyll fluorescence, Biomechanics, Flexural rigidity, Plant stress, Hydraulic laboratory

\section{Introduction}

Vegetation is investigated in hydraulics-related research fields for a variety of purposes that reflect its importance for fluvial morphodynamics (e.g. Bertoldi et al. 2015; Tal and Paola 2010), open-channel hydrodynamics (e.g. Marjoribanks et al. 2017; Siniscalchi and Nikora 2012), channel roughness (e.g. Aberle and Järvelä 2013; Järvelä 2005), coastal protection (e.g. Möller et al. 2014), and in studies of plant physiology and functioning (e.g. Dülger and 
Hussner 2017; Olesen and Sand-Jensen 1993). Some recent reviews on vegetated flows and the role of riverine vegetation as an ecosystem engineer (Folkard 2011; Gurnell 2014; Nepf 2012) reveal the booming interest in understanding how vegetation interacts with flowing water. Live vegetation is employed in hydraulic laboratories because it allows a representation of natural systems that is closer to reality than that obtained with artificial surrogates. While surrogates allow a more comprehensive control of experimental conditions and make experiments more replicable (Thomas et al. 2014), it is evident that simplistic surrogates, even when properly scaled, can behave differently from the vegetation prototypes (Aberle and Järvelä 2013; Vettori and Nikora 2019). Successful experiments with live vegetation, however, depend upon careful husbandry that is required to maintain the health of the organisms.

The increasing interest in research on freshwater macrophytes reflects the importance of the ecological and physical services that these plants provide (O'Hare et al. 2018). Submerged freshwater macrophytes have been mostly used in flume experiments to characterise their drag force and hydrodynamics (e.g. Biehle et al. 1998; Sand-Jensen 2003). Some recent studies have combined physical and biological observations (Asaeda et al. 2017). Previous research has shown that the biomechanical properties of freshwater macrophytes change significantly depending on the environment in which macrophytes live (Miler et al. 2014) or their growth stage (Loboda et al. 2018a). However, it is currently unknown whether the environmental conditions plants are exposed to in hydraulic laboratories affect their physiology and biomechanical properties significantly. This has important implications for the way in which plants interact with the flow, i.e. their drag force and reconfiguration, because significant variations in biomechanics are expected to alter plant hydrodynamics. A common dimensionless parameter to characterise plant hydrodynamics is the Cauchy number $C_{y}$, which describes the deformation of a body associated with the effect of the approach flow 
and is defined as $C_{y}=\rho U^{2} l^{3} w /(E I)$, where $\rho$ is water density, $U$ is the mean flow velocity, $l, w$, and $E I$ are the length, width and flexural rigidity of the plant (de Langre 2008). While measurements of plant biomechanical properties are obtained from standard mechanical tests (e.g. Biehle et al. 1998; Miler et al. 2014), plant health can be assessed with several techniques. For example, growth rate is commonly used as an indicator of plant health because it can be monitored easily (e.g. Asaeda and Rashid 2017; Madsen and Cedergreen 2002). But most flume experiments employing live plants investigate processes at short temporal scales (i.e. seconds to days), thus they would benefit from indicators that convey information of plant health at these relevant scales. Plants adapt to environmental conditions, including stressful conditions, via several processes that occur with different time scales: photosynthetic activity can change in a matter of seconds; changes in heat dissipation are effective within minutes; pigment content and leaf morphology take several days or weeks to modify (Ralph and Gademann 2005).

A suitable and robust technique to monitor plant health status is chlorophyll fluorescence analysis. This technique provides information about the photosynthetic activity in leaves by measuring the fluorescence signal re-emitted by chlorophyll pigments and is very sensitive to health stress (e.g. Murchie and Lawson 2013). Chlorophyll fluorescence analysis has been used to assess stress induced by light irradiance and/or chemicals in freshwater macrophytes (Hanelt et al. 2006; Hussner et al. 2010; Knauert et al. 2010; Marwood et al. 2001). A pivotal issue for progressing the understanding of interactions in water ecosystems is to assess if vegetation responses in a flume setting are representative of what happens in the natural environment. This study addresses this knowledge gap by assessing if environmental conditions typical of flume facilities cause physiological stress in freshwater macrophytes and induce significant biomechanical changes in them. In particular, we address the following research questions: (1) Can freshwater macrophytes be stressed by the environmental 
conditions typical in flume facilities and which abiotic factors cause significant plant stress? (2) Do the environmental conditions typical in flume facilities induce changes in the biomechanical properties of macrophytes? (3) Across a gradient of stress, are the maximum quantum yield of photosystem II (the chlorophyll fluorescence indicator used in this study) and plant biomechanical properties correlated? We present results from mesocosm experiments conducted with three freshwater macrophytes (Callitriche stagnalis, Myriophyllum verticillatum, and Potamogeton crispus). Plants were exposed to environmental conditions commonly found in hydraulic laboratories that were initially established using a survey completed by hydraulic researchers. Plant health status was monitored daily throughout the experiments and the biomechanics of plant stems was characterised at the end of the experiments.

\section{Materials and methods}

\subsection{Online survey}

Bornette and Puijalon (2011) report the following abiotic factors as the most significant causes of stress in freshwater macrophytes: light, temperature, characteristics of water, characteristics of substrate, and water movements. The present study focuses on the first three factors. To replicate conditions typical of flume facilities, we conducted an online survey among hydraulic researchers in May and June 2017. The results of the survey, completed by 26 researchers worldwide, are summarised in Table 1. It is worth noting that tap water is commonly used in flume facilities, with a few notable exceptions where river water or lake water is readily available.

According to the information collected, $27 \%$ of hydraulic researchers do not use live vegetation in their facilities, $19 \%$ use freshwater vegetation, $23 \%$ use saltwater vegetation, 
and $31 \%$ use both freshwater and saltwater species. Plants are kept in flume facilities from a few hours up to 2 weeks, with $71 \%$ of researchers keeping plants for up to five days. Most studies (70\%) are conducted using standard laboratory light conditions and in $87 \%$ of cases Photosynthetically Active Radiation (PAR) - that is, the amount of light that can be used by plants for photosynthesis - can be assumed to be inadequate for plants. Water temperature in flume facilities varies in a broad range between 5 and $30^{\circ} \mathrm{C}$. The conditions in which plants are tested depend on the plant species and the type of experiments performed, but in $52 \%$ of cases plants are rooted during tests.

\subsection{Mesocosm experiments}

Experiments were conducted using 3 freshwater species (C. stagnalis, M. verticillatum, and P. crispus, Fig. 1) that are widely distributed across the UK (Haslam 1978). Species with contrasting leaf morphology were chosen to encompass some of the diversity present in freshwater macrophytes (Fig. 1). Plants were collected by cutting the main stem above the roots and were then stored in moisturised bags for transport. Within 48 hours of collection plants were moved in $300 \mathrm{~L}$ aerated containers filled with water collected from a local pond rich in macrophytes. Before use, pond water was left to settle for 24 hours and filtered with a $53 \mu \mathrm{m}$ mesh sieve to remove micro-invertebrates and algae that could affect macrophyte health. The concentration of the main anions in the water was measured with an ionchromatograph (761 Compact IC, Metrohm AG, Herisau, Switzerland) and the total organic carbon with a TOC analyser (TOC-V CSN, Shimadzu, Kyoto, Japan). Pond water had a nonpurgeable organic carbon (NPOC) concentration equal to $4.20 \mathrm{ppm}$ and the following concentration of anions: $0.99 \mathrm{mg} / 1 \mathrm{NO}_{2}{ }^{-}, 8.79 \mathrm{mg} / 1 \mathrm{NO}_{3}{ }^{-}, 0 \mathrm{mg} / \mathrm{POO}_{4}{ }^{3-}, 0.27 \mathrm{mg} / \mathrm{l} \mathrm{F}^{-}, 44.77$ $\mathrm{Cl}^{-}, 48.35 \mathrm{SO}_{4}{ }^{2-}$. Before starting any experiment, plants were stored in the pond water for up to 3 days at a temperature between $17^{\circ} \mathrm{C}$ and $20.5^{\circ} \mathrm{C}$ and under a $14 \mathrm{~h}: 10 \mathrm{~h}$ day-night cycle 
with irradiance level at the water surface of approximately $150 \mu \mathrm{mol}_{\text {photon }} \mathrm{m}^{-2} \mathrm{~s}^{-1}$, similar to values typically reported in the relevant literature for cultivation of freshwater macrophtytes (e.g. Abernethy et al. 1996; Hussner et al. 2010).

Even though most researchers that participated in our survey indicated they used rooted plants, freshwater macrophytes can sustain normal growth via uptake of nutrients from water only (e.g. Bornette and Puijalon 2011; Madsen and Cedergreen 2002). For this reason and to simplify our experimental setup, at collection plants were cut above the roots. From the beginning to the end of our experiments, decrease in concentration of nutrients in water did not exceed $14 \%$ in pond water and $7 \%$ in tap water, respectively. Because of these small declines, we assume that lack of nutrients did not affect our results. P. crispus were tested between $17^{\text {th }}$ and $24^{\text {th }}$ August 2017, C. stagnalis were tested between $14^{\text {th }}$ and $20^{\text {th }}$ September 2017, and M. verticillatum were tested between $30^{\text {th }}$ September and $6^{\text {th }}$ October 2017.

Based on the information acquired with the survey, we designed five treatments: (i) use of unconditioned tap water, which differs from pond water in the concentration of anions (i.e. $0.68 \mathrm{mg} / \mathrm{l} \mathrm{NO}{ }^{-}, 11.05 \mathrm{mg} / \mathrm{NO}_{3}{ }^{-}, 3.35 \mathrm{mg} / 1 \mathrm{PO}_{4}{ }^{3-}, 0.17 \mathrm{mg} / \mathrm{l} \mathrm{F}^{-}, 49.68 \mathrm{mg} / \mathrm{l} \mathrm{Cl}^{-}, 100.86 \mathrm{mg} / \mathrm{l}$ $\mathrm{SO}_{4}{ }^{2-}, 2.59 \mathrm{ppm}$ NPOC); (ii) low water temperature; (iii) high water temperature; (iv) low irradiance level, i.e. with the use of standard ceiling lights; and (v) high irradiance level, with values of PAR similar to the maximum value reported in the survey. A summary of the characteristics of each treatment is reported in Table 2.

Each treatment mesocosm consisted of an $80 \mathrm{~L}$ plastic container filled with water to a depth of $28 \mathrm{~cm}$ that was aerated using air pumps. For all groups but 'Low Irradiance', irradiance level was maintained with fluorescent lighting units. To start each treatment, eight plants were randomly selected from the storage tanks and plastic labels were applied on them so that they could be recognized during the monitoring phase. Plants were then allotted to the 
dedicated mesocosm and homogeneously distributed throughout the container in order to prevent self-shading. Cooling and heating units, used for 'Low Temperature' and 'High Temperature', respectively, were activated once plants were already in the tanks to ensure a gradual temperature increase. Each treatment lasted five days, during which time plants were exposed to a 14h:10h day-night cycle. The health status of each plant was monitored on a daily basis (from day 1 to day 5) using a chlorophyll fluorometer. At the end of the 5-day treatment period, plants were removed from the mesocosms and their morphological and mechanical properties were investigated.

To assess the effects of storage conditions on plant health status, eight plants were randomly selected from the storage tanks within $48 \mathrm{~h}$ of collection and their conditions were monitored on a daily basis. This group is henceforth referred to as 'Pond Water' treatment (Table 2). Additionally, a control group made of eight plants were randomly selected from the storage tanks within three days of collection and their biomechanical properties were investigated immediately.

\subsection{Chlorophyll fluorescence}

Chlorophyll fluorescence analysis and its potential applications in plant physiology have been widely reviewed (Baker 2008; Baker and Rosenqvist 2004; Maxwell and Johnson 2000; Murchie and Lawson 2013). Here, we provide a brief description of the method and the experimental procedure followed in this study. Chlorophyll fluorometers measure the fluorescence signal emitted by chlorophyll pigments and provide indirect measurements of the photosynthetic activity of photosystem II (PSII; Murchie and Lawson 2013). Chlorophyll fluorometers measure photosynthetic activity in a non-intrusive and non-destructive way. For this reason they are promising tools to assess plant stress in hydraulic research. 
Among the parameters that can be obtained from measurements of chlorophyll fluorescence, the maximum quantum yield $F_{v} / F_{m}$ of PSII is the most robust indicator of plant health status, being sensitive to any stress causing photoinhibition or damage to PSII (e.g. Murchie and Lawson 2013). Regardless of the species, $F_{v} / F_{m}$ is commonly reported to be close to 0.83 in healthy, unstressed plants. Measurements of the maximum level of fluorescence $F_{m}$ and the minimum level of fluorescence $F_{0}=F_{m}-F_{v}$, where $F_{v}$ is the variable fluorescence, are taken in the Dark Adapted State (DAS), when plant material is adapted to conditions in which no actinic light is present (i.e. no photosynthetic activity occurs). The maximum level of fluorescence $F_{m}$ is measured right after the plant material has been exposed to a short saturating light pulse, the minimum level of fluorescence $F_{0}$ is measured in the dark (with only a measuring light on, Fig. 2b). To dark-adapt, a leaf/plant must not be exposed to actinic light for at least 20-30 minutes (e.g. Murchie and Lawson 2013).

The chlorophyll fluorometer used in this study is a Classic Fluorometer (Aquation Pty Ltd, Umina Beach, Australia). During experiments we measured the minimum level of fluorescence $F_{0}$ and the maximum level of fluorescence $F_{m}$. Following standard practice for plants exposed to suboptimal conditions (Murchie and Lawson 2013), chlorophyll fluorescence was monitored before dawn. During measurements, plants were exposed to an irradiance level of approximately $0.2 \mu \mathrm{mol}_{\text {photon }} \mathrm{m}^{-2} \mathrm{~s}^{-1}$, which would not trigger photosynthetic activity (Baker and Rosenqvist 2004). For each plant, before the treatment started, we selected a healthy leaf/group of leaves on which measurements were to be taken, the same leaf/group of leaflets was used throughout the experiments. Following a protocol common in botanical research, the youngest mature leaf/group of leaflets was selected. Leaves of $P$. crispus (Fig. 1a) were big enough so that measurements could be performed relatively easily on a single leaf. For C. stagnalis, leaves were too small in size (Fig. 1b) for a single leaf to 
cover the testing area of the chlorophyll fluorometer, therefore measurements were taken on the rosette at the top of the stem. For M. verticillatum, feathery leaflets (Fig. 1c) were clumped together to form a quasi-homogenous surface on which measurements could be made. It is important to note that different testing area sizes would produce different measurements of chlorophyll fluorescence parameters $F_{0}$ and $F_{m}$. However, since we analysed the ratio $F_{v} / F_{m}$ the size of the testing area did not affect the results.

\subsection{Biomechanical tests}

At the end of a treatment, plants were removed from the mesocosm, washed with unfiltered water, dried, and their mass density $\rho$ was measured via volumetric displacement. From each plant two samples were prepared from the top part of the stem and two samples from the bottom part of the stem because mechanical and morphological properties of Callitriche spp., P. crispus, and Myriophyllum spp. depend on the position along the stem (Miler et al. 2014, 2012). For each pair, one sample was used for uniaxial tensile tests and one for 3-point flexural tests. Samples were prepared from undamaged portions of stems and their morphology (e.g. length, diameter, cross-sectional area) was recorded. Once prepared, samples were stored in pondwater or tap water (depending on the treatment plants were exposed to) for up to 4 hours until mechanical test were performed. Each sample was removed from the water immediately before the test was conducted, so that drying effects would not impact the results (Łoboda et al. 2018b).

Mechanical tests were conducted using a benchtop testing machine (Instron Single Column 3343, Instron, High Wycombe, UK) equipped with a 50N load cell. Tests were conducted with a displacement rate equal to $10 \mathrm{~mm} / \mathrm{min}$ and lasted less than 1 minute. The manufacturer reports an accuracy of the force readings of $0.5 \%$ and that of displacement readings of $1 \%$. To minimize end-wall effects, samples for uniaxial tensile tests were prepared with a diameter to length ratio lower than 1:10 (Niklas 1992; Niklas and Spatz 
2012). Sample ends were positioned within screw, side-action grips and were protected using small metal pipes to preserve sample integrity during the tests (Miler et al. 2012). Samples for flexural tests were prepared with a diameter-to-span ratio as low as possible to minimize shear effects, bearing in mind that this ratio is recommended to be lower than 1:15 (Miler et al. 2012; Usherwood et al. 1997). To perform 3-point flexural tests, sample ends were supported at each end by two lower anvils, while an upper anvil applied a load at the centre. For tensile tests, data of force $F$ and displacement $\delta$ were converted into nominal stress $\sigma$ and strain $\varepsilon$, from which the tensile Young's modulus $E_{t}$ was calculated as the slope of the linear (elastic) part of the stress-strain curve (Fig. 3a). From 3-point flexural tests, data of force and displacement were used to calculate the flexural rigidity $E_{b} I$ using the formula $E_{b} I=$ $\left(s^{3} F / \delta\right) / 48$, where $E_{b}$ is the flexural Young's modulus, $I$ is the moment of inertia, $s$ is the sample span, and $F / \delta$ is the slope of the initial part of the force-displacement curve (Fig. 3b).

\subsection{Statistical analysis}

All data post-processing and statistical analyses were conducted using MATLAB Release 2016a (The MathWorks, Inc., Natick, Massachusetts, USA). Given the strong dispersion in biological variables, significance for all statistical analyses was set at $\alpha=0.10$. Further to significance, eta squared $\eta^{2}$ was calculated as measure of the effect size.

\subsubsection{Plant health status}

For $F_{v} / F_{m}$, two metrics were used to assess physiological response of each plant to a treatment: (i) the slope $m_{F}$ of a linear regression model of $F_{v} / F_{m}$ in time calculated using the least square method, and (ii) the absolute value $F_{v} / F_{m 5}$ on the last day of experiments. First, statistical analysis was conducted for each species independently. Differences in health status between treatments were tested with one-way ANOVA and Tukey's Honestly Significant Differences (HSD) test corrected with the Bonferroni technique (e.g. Hochberg and Tamhane 
1987). Differences in metrics between species and treatments were tested with generalized linear models (GLMs) including potential interactions between species and treatment. For all models, visual inspection of residual plots did not reveal any obvious deviations from assumptions of normality and homoscedasticity.

\subsubsection{Plant biomechanics}

Statistical analysis was conducted for each species and location along the stem (i.e. top and bottom) separately, because these factors significantly affect the biomechanics of freshwater macrophytes (Miler et al. 2014). For each biomechanical property considered we tested differences between treatments and the control group using multiple pairwise comparisons with one-way ANOVA. The significance level of each test was corrected using the percomparison error rate to account for multiple non-independent tests. Mass density differences between treatments and species were tested using two-way ANOVA and Tukey's Honestly Significant Differences (HSD) test corrected with the Bonferroni technique. Location along the stem was not included as a factor because $\rho$ was measured using whole plants.

Differences in biomechanical properties between species, treatments and locations along the stem were tested with GLMs including potential interactions between species and treatment and between species and location along the stem. In some cases, parameters were transformed to achieve normality and homogeneity of variance of the residuals and/or outliers were removed. For all models described here, visual inspection of residual plots did not reveal any obvious deviations from assumptions of normality and homoscedasticity. 


\section{Results}

\subsection{Plant health status}

\subsubsection{Effects of treatments on each species}

For P. crispus 'Tap Water' and 'Low Irradiance' were characterised by a high percentage of invalid $F_{v} / F_{m}$ measurements because many leaves underwent severe deterioration. Thus, these two treatments were not included in the analysis of the slope and the day 5 value of $F_{v} / F_{m}$ (Table 3 ). As an alternative, after setting invalid $F_{v} / F_{m}$ equal to zero, we calculated the mean daily value $\overline{F_{v} / F_{m}}$ of $F_{v} / F_{m}$ across all plants within each treatment and compared the time series (Fig. 4a). It is evident from Fig. 4a that the trend of both 'Tap Water' and 'Low Irradiance' is considerably different (slope $=-0.12$ to $-0.13 \mathrm{~d}^{-1}$ ) from that of the remaining treatments (slope $=-0.01$ to $-0.02 \mathrm{~d}^{-1}$ ). Moreover, the 'Low Temperature' treatment had a marginally significant effect on health status $\left(m_{F}, \mathrm{p}=0.134\right.$; Fig. $\left.4 \mathrm{~b}\right)$.

For C. stagnalis treatments did not have any significant effect on $F_{v} / F_{m 5}$ or $m_{F}$ (Table 3). For $M$. verticillatum the highest values of $F_{v} / F_{m 5}$ were not associated with 'Pond Water' but with 'Low Temperature'. For this reason, values of $F_{v} / F_{m-d 5}$ and $m_{F}$ of treatments were compared with those of 'Low Temperature'. Both 'Tap Water' $\left(F_{v} / F_{m 5}, \mathrm{p}=0.058\right)$ and 'Low Irradiance' $\left(m_{F}, \mathrm{p}=0.014\right)$ were found to reduce plant health status.

Before analysis, all parameters were tested for homogeneity of variance using the Brown-Forsythe test. The parameter $m_{F}$ for $M$. verticillatum did not have homogenous variance (see supplementary material), however no transformation of data that would achieve homoscedasticity was found. One-way ANOVA was used nonetheless because the sample size was relatively large, i.e. more than five treatments with more than six samples per treatment (Underwood 1997). 


\subsubsection{Interspecies comparison}

Both $C$. stagnalis and $M$. verticillatum were characterised by values of $F_{v} / F_{m 5}$ lower than those of $P$. crispus, while 'Tap Water' was the only treatment inducing a significant decline in health (Table 4). The GLM for $F_{v} / F_{m 5}$ is able to describe only $17 \%$ of the variance (Table 4) possibly because data are skewed (skewness $=-1.525$ ) due to the nature of $F_{v} / F_{m}$. Results of GLM for $m_{F}$ indicate that there was a significant difference between $M$. verticillatum and the other species (Table 4) and significant interactions between species and treatments were present (not shown). Unfortunately, the ability of GLMs to characterise the effects of treatments across species is limited by the lack of data from 'Tap Water' and 'Low Irradiance' for $P$. crispus, with only two samples available for each treatment. Overall, results of GLMs of $F_{v} / F_{m 5}$ and $m_{F}$ indicate that species is the most important factor for these metrics, while different treatments had different effects depending on the species and the metric used in the analysis.

\subsection{Plant biomechanics}

\subsubsection{Effects of treatments on each species}

The mean values and standard deviations of the cross-sectional surface area $A_{x s}$, moment of inertia $I$, mass density $\rho$, tensile Young's modulus $E_{t}$, flexural Young's modulus $E_{b}$ and flexural rigidity $E_{b} I$ for plants of the control group are reported in Table 5 for each species investigated. However, in this section we focus attention on most important biomechanical properties for defining plant hydraulic performance, i.e. $\rho, E_{t}$, and $E_{b} I$.

No treatments significantly affected the mass density for any species (two-way ANOVA, treatment: $p=0.118, \eta^{2}=0.052$ ), but several treatments significantly affected the tensile Young's modulus or flexural rigidity of species investigated (Table 6). For P. crispus, changes in $E_{t}$ associated with 'Tap Water' and 'Low Temperature' occurred at the bottom 
and top of stems, respectively. Flexural rigidity reduced significantly with 'Low Irradiance' at the top of stems (Table 6).

Due to a power cut at the institute, after being prepared, testing samples of the control group for C. stagnalis were left for 24 hours in pond water before being used in mechanical tests. This additional storage time probably affected the biomechanical properties of the samples, so results of mechanical tests on those samples were not used for analysis, which was conducted using samples of 'Pond Water' as a control group. For the top parts of the stems 'High Temperature' and both irradiance treatments induced a reduction in $E_{b} I$ (Table 6).

Treatments inducing variations in the biomechanical properties of $M$. verticillatum were 'Tap Water' and 'Low Irradiance', the first reduced $E_{b} I$ at the top of stems, the latter induced a decline in $E_{t}$ at the top of stems (Table 6). The 'Low Irradiance' treatment was associated with declines in $E_{t}$ or $E_{b} I$ for all species, and 'Tap Water' was associated with changes in these properties for two species. The flexural rigidity at the top of stems reduced for all species as a result of either treatments.

\subsubsection{Interspecies comparison}

For the mass density, interactions between treatments and species were not significant (twoway ANOVA, treatment $\mathrm{x}$ species: $\mathrm{p}=0.886, \eta^{2}=0.033$ ) and effect of treatments was marginally significant, but with small effect size compared to that of species (two-way ANOVA, species: $\left.\mathrm{F}_{2,147}=17.28, \mathrm{p} \ll 0.01, \eta^{2}=0.174\right)$. No difference in the mass density of P. crispus and C. stagnalis was identified (Tukey's HDS, $\Delta=-16.2 \pm 50 \mathrm{~g} \mathrm{dm}^{-3}, \mathrm{p}=1$ ), while the mass density of $M$. verticillatum was significantly lower than that of the other two species (Tukey's HDS, P. crispus: $\Delta=-96.6 \pm 50 \mathrm{~g} \mathrm{dm}^{-3}, \mathrm{p} \ll 0.01$; $C$. stagnalis: $\Delta=-113 \pm 50 \mathrm{~g}$ $\left.\mathrm{dm}^{-3}, \mathrm{p} \ll 0.01\right)$ 
The tensile Young's modulus was not significantly affected by interactions between species and treatment (species $\times$ treatment: $\mathrm{F}_{10,251}=1.33, \mathrm{p}=0.213, \eta^{2}=0.031$ ), hence effects of treatments on $E_{t}$ could be discussed independently of species. The GLM describes $56 \%$ of the variance (Table 7) and indicates that species is by far the most important factor (species: $\mathrm{F}_{2,251}=69, \mathrm{p} \ll 0.01, \eta^{2}=0.332$ ), followed by interactions between species and location along the stem (species $\times$ location: $\mathrm{F}_{2,251}=10.8, \mathrm{p} \ll 0.01, \eta^{2}=0.05$ ) and location along the stem (location: $F_{1,251}=9.93, p=0.002, \eta^{2}=0.024$ ) which, however, show a small effect size. The species with the stiffest stems was $P$. crispus, followed by $C$. stagnalis and M. verticillatum (Table 7).

Interactions between treatment and species in the model of flexural rigidity $E_{b} I$ (species $\times$ treatment: $F_{10,273}=133, p=0.062, \eta^{2}=0.013$ ) were significant but with a small effect size, therefore they were removed. Species was the most important factor (species: $F_{2,273}=$ $373, \mathrm{p} \ll 0.01, \eta^{2}=0.546$ ), followed by location along the stem (location: $\mathrm{F}_{1,273}=294, \mathrm{p} \ll$ $\left.0.01, \eta^{2}=0.215\right)$ and interactions between the two factors (species $\times$ location: $F_{2,273}=30.8, p$ $\ll 0.01, \eta^{2}=0.046$; Table 7). The species with the highest flexural rigidity was $P$. crispus followed by $M$. verticillatum and $C$. stagnalis (Table 7). In general, species and location along the stem were the most significant factors to define plant biomechanics, with species showing significantly different values of $E_{b} I, E_{t}$ and $\rho$.

\subsubsection{Health status as predictor of variations in biomechanics}

Potential correlations between biomechanical properties $E_{t}, E_{b} I$ and $F_{v} / F_{m 5}$ were investigated within a generalized linear model framework. Species, location along the stem and $F_{v} / F_{m 5}$ were entered as factors, including two-way interactions. In all cases the model described a good portion of the deviance. For $E_{t}, F_{v} / F_{m 5}$ had a considerable effect on the estimate, but the associated error was large, hence the effect was not significant (Table 8). 
Further, including $F_{v} / F_{m 5}$ in the model led to a marginal increase of $\mathrm{R}^{2}$ adj from 0.563 (for the case in which only species and location are considered) to 0.568 . The interactions between species and $F_{v} / F_{m 5}$ was marginally significant (not shown in Table 8 ). For $E_{b} I$, interactions between species and $F_{v} / F_{m 5}$ could be removed from the model (species $\times F_{v} / F_{m 5}$ : LR Stat $=$ 2.606, $\mathrm{p}=0.272)$. The factor $F_{v} / F_{m 5}$ had a significant effect even though the standard error associated with it was large (Table 8 ). Including $F_{v} / F_{m 5}$ in the model increased $\mathrm{R}^{2}$ adj from 0.788 to 0.811 . The effect of $F_{v} / F_{m 5}$ on $E_{b} I$ and $E_{t}$ was always positive - after the relevant transformation is taken into account - that is, higher values of $F_{v} / F_{m 5}$ (i.e. healthier plants) were associated with more rigid stems.

\section{Discussion}

\subsection{Plant health status}

During the experimental period plant health declined in all species. Even for plants in 'Pond Water', designed to minimize plant stress, $F_{v} / F_{m}$ reduced significantly (t-test for slope equal to $0:$ P. crispus, $\mathrm{t}=-4.606, \mathrm{p}=0.003 ;$ C. stagnalis, $\mathrm{t}=-3.145, \mathrm{p}=0.016 ;$ M. verticillatum, $\mathrm{t}=$ $-2.320, \mathrm{p}=0.054)$, indicating that plants were exposed to suboptimal conditions. However, plants can be tolerant and continue to live in suboptimal conditions, therefore showing nonstationary health status. The key issue for hydraulic experiments is whether the physiological or biomechanical adaptation to reduced health also leads to alterations in biophysical properties that affect plant-flow interactions.

Species is the most important factor for the estimation of $F_{v} / F_{m}$ (Table 4$)$, and each species appears to react differently to treatments (Fig. 4), with different values of $F_{v} / F_{m}$ for different species. However, low irradiance and exposure to tap water caused stress in two out of three species, suggesting that there may be some general patterns. The strong effect that 
low irradiance and tap water had on $F_{v} / F_{m}$ of $P$. crispus and $M$. verticillatum can be ascribed to different causes. The 'Low Irradiance' treatment did not provide enough irradiance to exceed the light compensation point for plants; that is, the amount of light required for the rate of photosynthesis to match respiration rate (i.e. so that a plant can store nutrients and grow). The cause of reduced health in 'Tap Water' is not clear and may be due to high conductivity (Table 1), high concentration of sulphate (e.g. Davies 2007; Simmons 2012) and/or low concentration of $\mathrm{CO}_{2}$ associated with a limited presence of microorganisms compared to pond water. We hypothesise that $C$. stagnalis was not significantly affected by these treatments because it is a perennial species and, as such, it is adapted to a wider range of conditions (Preston and Croft 1997), which may include very low light irradiances.

We believe that seasonality and plant phenology played an important role in the experiments with $P$. crispus. The high sensitivity of $P$. crispus to tap water and low irradiance conditions can be related to the period when these plants were tested, i.e. with turions already present. This indicates that the plants had already invested nutrients to ensure vegetation spread in the autumn and were therefore already deteriorating (Catling and Dobson 1985; Chambers et al. 1985).

\subsection{Plant biomechanics and implications for hydraulic performance}

Several treatments were associated with significant changes in plant biomechanical properties, but results were strongly dependant on the species and varied depending on the biomechanical property considered (Table 6). The effects of treatments on plant biomechanics were somewhat similar for P. crispus and $M$. verticillatum. Interestingly, biomechanical properties at breakage, such as toughness, were not significantly affected by any treatments (shown in supplementary material), suggesting that stiffness and rigidity are more sensitive to environmental conditions and respond more quickly to plant physiology. 
For all properties considered in this study, results of GLMs indicate that treatments did not have significant or considerable effects on plant biomechanics. While this type of analysis can identify patterns common for all species and treatments, it is evident that in a speciesdependent scenario in which different treatments induce different effects, as here, it is more relevant to focus attention on the effects of a specific treatment on each species.

Notwithstanding the high variability intrinsic in plant biomechanics (Niklas and Spatz 2012), 'Tap Water' and/or 'Low Irradiance', which were identified as the most stressful for plants, induced considerable variations in stem stiffness of all species, especially at the top part of stems (Table 6). The range of variations in biomechanical properties in this study was between $29 \%$ and $68 \%$ of the values of the control group. Changes in $E_{b} I$ were associated with significant reduction in $E_{b}$ for $C$. stagnalis and $M$. verticillatum and significant reduction in $I$ for $P$. crispus (shown in supplementary material). While these variations are statistically significant and seem quite large, they need contextualising. The hydraulic performance of vegetation is commonly evaluated with the Cauchy number $C_{y}$, which describes vegetation flexibility as a response to flow action (e.g. de Langre 2008). Due to the nature of the Cauchy number, important variations in plant behaviour occur across orders of magnitude of $C_{y}$. Therefore, the variations reported in this study are not expected to change the biomechanics of plant stems sufficiently to cause a significant modification of plant hydraulic performance. Nevertheless, it is expected that treatments that induce changes in stem biomechanics would also induce variations in the mechanical properties of petioles and leaves. These effects, which have not been investigated in the current study, may have a major impact on the interactions of a plant with the flow. Aberle and Järvelä (2013) argued that the role of leaves is crucial in the characterisation of the drag force of riparian vegetation. Similarly, we expect the role of leaves to be important for the hydraulic performance of submerged freshwater macrophytes. Further, we expect the effects of plant stress on leaves 
and petioles, which are crucial in determining the orientation (and drag) of leaves (Tadrist et al. 2014), to be more significant and faster to detect compared to the effects on the main stem. For example, Albayrak et al. (2012) and Vettori and Nikora (2018) reported that blades/leaves with lower flexural rigidity experienced lower drag force.

\subsection{Linking plant health status and biomechanics}

Independent analysis of plant health status and biomechanics revealed that exposure to tap water and low irradiance conditions caused a reduction in $F_{v} / F_{m}$ and in stem stiffness or flexural rigidity in both $P$. crispus and $M$. verticillatum. Further, in $88 \%$ of cases where biomechanical variations occurred and in all cases where variations occurred at the top of stems, stiffness or flexural rigidity declined (Table 3). Therefore, it is pertinent to ask if there is a correlation between $F_{v} / F_{m}$ on leaves and plant biomechanics and if $F_{v} / F_{m}$ can be used as metric to predict stress-related changes in biomechanics. Results of LME models indicate that $F_{v} / F_{m}$ was positively correlated with all biomechanical properties considered, but it was the least significant factor among those included in the models (Table 8). Our model of $\log \left(E_{b} I\right)$ describes up to $81 \%$ of variance (Table 8), thus providing a tool to estimate flexural rigidity of a species based on the location along a stem and its value of $F_{v} / F_{m}$. The accuracy of the model with $F_{v} / F_{m}\left(\mathrm{R}^{2}\right.$ adj $=0.811$, Table 8$)$ surpasses that of the model with description of treatments $\left(\mathrm{R}^{2}\right.$ adj $=0.800$, Table 7$)$ and that of the model without $F_{v} / F_{m}\left(\mathrm{R}^{2}\right.$ adj $\left.=0.788\right)$, indicating that $F_{v} / F_{m}$ can be used as simple metric to characterise the effects of environmental conditions on plant biomechanics. Nevertheless, species and location along a stem are the most important factors for defining flexural rigidity. Bearing in mind that $E_{b} I$ (together with the mass density) is the most important biomechanical property to parameterise the resistance of vegetation to a flow, these findings are important in hydraulic applications. 
The present study has attempted, for the first time, to link the physiology and biomechanics of freshwater macrophytes. Our results provide evidence that some correlation between plant health status and stiffness/rigidity exists, which highlights the importance of additional investigations of the role of plant physiology in flow-plant interactions and hydraulic experiments. Even though we found a correlation between $F_{v} / F_{m}$ and $\log \left(E_{b} I\right)$ for plant stems, the metric $F_{v} / F_{m}$ may be better correlated with the flexural rigidity of leaves and/or petioles, because these plant components are constituted by softer tissues. Moreover, other physiological parameters important in plant signalling networks, such as reactive oxygen species investigated by Asaeda et al. (2017) and Asaeda and Rashid (2017), may provide a stronger link between plant health status and plant biomechanics.

To acquire a better understanding of the connections between plant physiology, plant biomechanics and flow-plant interactions, we propose that measurements of plant health status should be made as a standard part of hydraulic experiments. This would generate a dataset of plant health status and plant performance measurements that could be used to develop a fuller understanding of the links between plant physiology and hydrodynamics. Developing stronger interdisciplinary collaborations, for example with plant ecologists, is critical for achieving such understanding. We recommend that future research in this area focuses on the following key issues: (1) identifying the indicator of plant health status which most strongly correlates with plant biophysical properties; (2) conducting experiments with different stressors and different species to identify common and potentially universal patterns; (3) characterising the effects of stressors on the biomechanical properties of leaves and petioles; and (4) investigating the effects of gradients of plant stress on flow-plant interactions. 


\section{Conclusions}

Typical environmental conditions in hydraulic laboratories can unduly stress freshwater macrophytes. While the effects of abiotic factors depend on species and seasonality, exposure to tap water and irradiance below the light compensation point caused major stress to the plants examined here. Typical laboratory conditions can also induce significant variations in plant biomechanical properties, with flexural rigidity at the top of stems being the most sensitive to changes and stem stiffness or flexural rigidity declining in most cases. The metric $F_{v} / F_{m}$, obtained from chlorophyll fluorescence measurements on dark adapted leaves, had a significant positive correlation with $E_{b} I$ and $E_{t}$ of plant stems. Also, we showed that $F_{v} / F_{m}$ can be used to estimate the flexural rigidity of plant stems for individual species and specific locations along the plant stem..

These findings have significant implications for the use of live vegetation in hydraulic laboratories. If hydraulic researchers do not provide freshwater macrophytes with appropriate husbandry, even a short storage time (e.g. 5 days) can negatively affect plant physiology and make plant stems more flexible, potentially invalidating experiments designed to measure the impact of healthy plants on flow properties. The effects of plant stress on the hydraulic performance of freshwater macrophytes will be addressed in a future manuscript. Measurements of physiological parameters such as $F_{v} / F_{m}$ are simple and effective tools to evaluate plants health status. These measurements can provide important indirect information about plant biomechanical properties such as flexural rigidity. To facilitate fuller understanding of the relations between plant health, biomechanics, and interactions with water flow we recommend that plant health status is measured as standard practice (as one might monitor temperature or flow velocity) during hydraulic experiments with live vegetation. Pending further research the maximum quantum yield of PSII, measured using 
Chlorophyll Fluorescence, is a suitable measurement of health status that is widely achievable. 


\section{Acknowledgments}

The authors are grateful to Rebecca McKenzie and Richard Harland for technical support, Jon Millett for helpful discussion in the preliminary stage of the project, and Richard Mason, Kate Mathers, and Harry Sanders for logistical help. A big thank you to all colleagues that completed our online survey and shared their experiences with us.

\section{Disclosure statement}

No potential conflict of interest was reported by the authors.

\section{Funding}

The work described in this publication was supported by the European Community's Horizon 2020 Programme through the grant to the budget of the Integrated Infrastructure Initiative HYDRALAB+, Contract no. 654110. 


\section{References}

Aberle, J., Järvelä, J., 2013. Flow resistance of emergent rigid and flexible floodplain vegetation. J. Hydraul. Res. 51, 33-45. https://doi.org/10.1080/00221686.2012.754795

Abernethy, V.J., Sabbatini, M.R., Murphy, K.J., 1996. Response of Elodea canadensis Michx, and Myriophyllum spicatum L. to shade, cutting and competition in experimental culture. Hydrobiologia 340, 219-224. https://doi.org/10.1007/BF00012758

Albayrak, I., Nikora, V., Miler, O., O’Hare, M., 2012. Flow-plant interactions at a leaf scale: Effects of leaf shape, serration, roughness and flexural rigidity. Aquat. Sci. 74, 267-286. https://doi.org/10.1007/s00027-011-0220-9

Asaeda, T., Rashid, M.H., 2017. Limnologica Effects of turbulence motion on the growth and physiology of aquatic plants. Limnologica 62, 181-187. https://doi.org/10.1016/j.limno.2016.02.006

Asaeda, T., Sanjaya, K., Kaneko, Y., 2017. Effects of mechanical stressors caused by mean flow and turbulence on aquatic plants with different morphologies. Ecohydrology 10, 113. https://doi.org/10.1002/eco.1873

Baker, N.R., 2008. Chlorophyll Fluorescence: A Probe of Photosynthesis In Vivo. Annu. Rev. Plant Biol. 59, 89-113. https://doi.org/10.1146/annurev.arplant.59.032607.092759

Baker, N.R., Rosenqvist, E., 2004. Applications of chlorophyll fluorescence can improve crop production strategies: an examination of future possibilities. J. Exp. Bot. 55, 16071621. https://doi.org/10.1093/jxb/erh196

Bal, K., Bouma, T.J., Buis, K., Struyf, E., Jonas, S., Backx, H., Meire, P., 2011. Trade-off between drag reduction and light interception of macrophytes: Comparing five aquatic plants with contrasting morphology. Funct. Ecol. 25, 1197-1205. https://doi.org/10.1111/j.1365-2435.2011.01909.x

Bertoldi, W., Welber, M., Gurnell, A.M., Mao, L., Comiti, F., Tal, M., 2015. Physical modelling of the combined effect of vegetation and wood on river morphology. Geomorphology 246, 178-187. https://doi.org/10.1016/j.geomorph.2015.05.038

Biehle, G., Speck, T., Spatz, H.-C., 1998. Hydrodynamics and biomechanics of the submerged water moss Fontinalis antipyretica - A comparison of specimens from habitats with different flow velocities. Bot. Acta 111, 42-50. https://doi.org/10.1111/j.1438-8677.1998.tb00675.x 
Bornette, G., Puijalon, S., 2011. Response of aquatic plants to abiotic factors: a review. Aquat. Sci. 73, 1-14. https://doi.org/10.1007/s00027-010-0162-7

Catling, P.M., Dobson, I., 1985. THE BIOLOGY OF CANADIAN WEEDS.: 69. Potamogeton crispus L. Can. J. plant Sci. 65, 655-668.

Chambers, P.A., Spence, D.H.N., Weeks, D.C., 1985. Photocontrol of turion formation by Potamogeton crispus L. in the laboratory and natural water. New Phytol. 99, 183-194.

Davies, T.D., 2007. Sulphate toxicity to the aquatic moss, Fontinalis antipyretica. Chemosphere 66, 444-451. https://doi.org/10.1016/j.chemosphere.2006.06.021

de Langre, E., 2008. Effects of Wind on Plants. Annu. Rev. Fluid Mech. 40, 141-168. https://doi.org/10.1146/annurev.fluid.40.111406.102135

Denny, M.W., Gaylord, B., 2002. The mechanics of wave-swept algae. J. Exp. Biol. 205, 1355-1362. https://doi.org/10.2307/2266149

Dülger, E., Hussner, A., 2017. Differences in the growth and physiological response of eight Myriophyllum species to carbon dioxide depletion. Aquat. Bot. 139, 25-31. https://doi.org/10.1016/j.aquabot.2017.02.008

Folkard, A.M., 2011. Vegetated flows in their environmental context: a review. Proc. Inst. Civ. Eng. - Eng. Comput. Mech. 164, 3-24. https://doi.org/10.1680/eacm.8.00006

Gurnell, A.M., 2014. Plants as river system engineers. Earth Surf. Process. Landforms 39, 4 25. https://doi.org/10.1002/esp.3397

Hanelt, D., Hawes, I., Rae, R., 2006. Reduction of UV-B radiation causes an enhancement of photoinhibition in high light stressed aquatic plants from New Zealand lakes. J. Photochem. Photobiol. B Biol. 84, 89-102. https://doi.org/10.1016/j.jphotobiol.2006.01.013

Haslam, S.M., 1978. River plants. Cambridge University Press, Cambridge.

Hochberg, J., Tamhane, A., 1987. Multiple comparison procedures. John Wiley \& Sons, New York.

Hussner, A., Hoelken, H.P., Jahns, P., 2010. Low light acclimated submerged freshwater plants show a pronounced sensitivity to increasing irradiances. Aquat. Bot. 93, 17-24. https://doi.org/10.1016/j.aquabot.2010.02.003

Järvelä, J., 2005. Effect of submerged flexible vegetation on flow structure and resistance. J. 
Hydrol. 307, 233-241. https://doi.org/10.1016/j.jhydrol.2004.10.013

Knauert, S., Singer, H., Hollender, J., Knauer, K., 2010. Phytotoxicity of atrazine, isoproturon, and diuron to submersed macrophytes in outdoor mesocosms. Environ. Pollut. 158, 167-174. https://doi.org/10.1016/j.envpol.2009.07.023

Łoboda, A.M., Bialik, R.J., Karpiński, M., Przyborowski, Ł., 2018a. Seasonal changes in the biomechanical properties of Elodea canadensis Michx. Aquat. Bot. 147, 43-51. https://doi.org/10.1016/j.aquabot.2018.03.006

Łoboda, A.M., Przyborowski, Ł., Karpiński, M., Bialik, R.J., Nikora, V., $2018 b$. Biomechanical properties of aquatic plants: The effect of test conditions. Limnol. Oceanogr. Methods 16, 222-236. https://doi.org/10.1002/lom3.10239

Madsen, T. V, Cedergreen, N., 2002. Sources of nutrients to rooted submerged macrophytes growing in a nutrient-rich stream. Freshw. Biol. 47, 283-291.

Marjoribanks, T.I., Hardy, R.J., Lane, S.N., Parsons, D.R., 2017. Does the canopy mixing layer model apply to highly flexible aquatic vegetation? Insights from numerical modelling. Environ. Fluid Mech. 17, 277-301. https://doi.org/10.1007/s10652-0169482-Z

Marwood, C.A., Solomon, K.R., Greenberg, B.M., 2001. Chlorophyll fluorescence as a bioindicator of effects on growth in aquatic macrophytes from mixtures of polycyclic aromatic hydrocarbons. Environ. Toxicol. Chem. 20, 890-898.

Maxwell, K., Johnson, G.N., 2000. Chlorophyll fluorescence - a practical guide. J. Exp. Bot. 51, 659-668.

Miler, O., Albayrak, I., Nikora, V., O’Hare, M., 2014. Biomechanical properties and morphological characteristics of lake and river plants: implications for adaptations to flow conditions. Aquat. Sci. 76, 465-481. https://doi.org/10.1007/s00027-014-0347-6

Miler, O., Albayrak, I., Nikora, V., O’Hare, M., 2012. Biomechanical properties of aquatic plants and their effects on plant-flow interactions in streams and rivers. Aquat. Sci. 74, 31-44. https://doi.org/10.1007/s00027-011-0188-5

Möller, I., Kudella, M., Rupprecht, F., Spencer, T., Paul, M., Van Wesenbeeck, B.K., Wolters, G., Jensen, K., Bouma, T.J., Miranda-Lange, M., 2014. Wave attenuation over coastal salt marshes under storm surge conditions. Nat. Geosci. 7, 727-731. 
Murchie, E.H., Lawson, T., 2013. Chlorophyll fluorescence analysis: a guide to good practice and understanding some new applications. J. Exp. Bot. 64, 3983-3998. https://doi.org/10.1093/jxb/ert208

Nepf, H.M., 2012. Hydrodynamics of vegetated channels Hydrodynamics of vegetated channels. J. Hydraul. Res. 50, 262-279.

Niklas, K.J., 1992. Plant biomechanics: an engineering approach to plant form and function. University of Chicago Press, Chicago.

Niklas, K.J., Spatz, H.-C., 2012. Plant physics. University of Chicago Press, Chicago.

O’Hare, M., Aguiar, F.C., Asaeda, T., Bakker, E.S., Chambers, P.A., Clayton, J.S., Elger, A., Ferreira, T.M., Gross, E.M., Gunn, I.D.M., Gurnell, A.M., Hellsten, S., Hofstra, D.E., Li, W., Mohr, S., Puijalon, S., Szoszkiewicz, K., Willby, N.J., Wood, K.A., 2018. Plants in aquatic ecosystems: current trends and future directions. Hydrobiologia 812, 1-11. https://doi.org/10.1007/s10750-017-3190-7

Olesen, B., Sand-jensen, K., 1993. Seasonal acclimatization of eelarass Zostera marina growth to light. Mar. Ecol. Prog. Ser. 94, 91-99.

Preston, C.D., Croft, J., 1997. Aquatic plants in Britain and Ireland. Harley Books, Colchester.

Puijalon, S., Léna, J.P., Rivière, N., Champagne, J.Y., Rostan, J.C., Bornette, G., 2008. Phenotypic plasticity in response to mechanical stress : hydrodynamic performance and fitness of four aquatic plant species. New Phytol. 177, 907-917.

Ralph, P.J., Gademann, R., 2005. Rapid light curves: A powerful tool to assess photosynthetic activity. Aquat. Bot. 82, 222-237. https://doi.org/10.1016/j.aquabot.2005.02.006

Sand-Jensen, K., 2003. Drag and reconfiguration of freshwater macrophytes. Freshw. Biol. 48, 271-283. https://doi.org/10.1046/j.1365-2427.2003.00998.x

Simmons, J.A., 2012. Toxicity of major cations and anions ( $\mathrm{Na}+, \mathrm{K}+, \mathrm{Ca} 2+, \mathrm{Cl}-$, and $\mathrm{SO})$ to a macrophyte and an alga. Environ. Toxicol. Chem. 31, 1370-1374.

Siniscalchi, F., Nikora, V., 2012. Flow-plant interactions in open-channel flows: A comparative analysis of five freshwater plant species. Water Resour. Res. 48, 1-13. https://doi.org/10.1029/2011WR011557 
Tadrist, L., Saudreau, M., de Langre, E., 2014. Wind and gravity mechanical effects on leaf inclination angles. J. Theor. Biol. 341, 9-16. https://doi.org/10.1016/j.jtbi.2013.09.025

Tal, M., Paola, C., 2010. Effects of vegetation on channel morphodynamics: Results and insights from laboratory experiments. Earth Surf. Process. Landforms 35, 1014-1028. https://doi.org/10.1002/esp.1908

Thomas, R.E., Johnson, M.F., Frostick, L.E., Parsons, D.R., Bouma, T.J., Dijkstra, J.T., Eiff, O., Gobert, S., Henry, P.-Y., Kemp, P., McLelland, S.J., Moulin, F.Y., Myrhaug, D., Neyts, A., Paul, M., Penning, W.E., Puijalon, S., Rice, S.P., Stanica, A., Tagliapietra, D., Tal, M., Tørum, A., Vousdoukas, M.I., 2014. Physical modelling of water, fauna and flora: Knowledge gaps, avenues for future research and infrastructural needs. J. Hydraul. Res. 52, 311-325. https://doi.org/10.1080/00221686.2013.876453

Underwood, A.J., 1997. Experiments in ecology: their logical design and interpretation using analysis of variance. Cambridge University Press, Cambridge.

Usherwood, J.R., Ennos, A.R., Ball, D.J., 1997. Mechanical and anatomical adaptations in terrestrial and aquatic buttercups to their respective environments. J. Exp. Bot. 48, 1469-1475. https://doi.org/10.1093/jxb/48.7.1469

Vettori, D., Nikora, V., 2018. Flow-seaweed interactions: a laboratory study using blade models. Environ. Fluid Mech. 18. https://doi.org/10.1007/s10652-017-9556-6

Vettori, D., Nikora, V., 2019. Hydrodynamic performance of vegetation surrogates in hydraulic studies: a comparative analysis of seaweed blades and their physical models. J. Hydraul. Res. https://doi.org/10.1080/00221686.2018.1562999 


\section{Tables and figures}

Table 1 Results of survey of hydraulic researchers on standard practices in flume facilities. Note that the survey was completed by researchers using any type of vegetation. PAR is the acronym of Photosynthetically Active Radiation.

\begin{tabular}{|c|c|c|}
\hline & Summary of results & Most relevant result \\
\hline Time in which & Less than 1 day in $24 \%$ of cases & Up to 5 days in $71 \%$ of cases \\
\hline plants are kept & Between 1 and 2 days in $33 \%$ of cases & \\
\hline \multirow[t]{2}{*}{ in a flume } & More than 2 days in $43 \%$ of cases & \\
\hline & More than 5 days in $29 \%$ of cases & \\
\hline \multirow[t]{4}{*}{ Light conditions } & Light that provides adequate PAR used in $13 \%$ & Standard laboratory light conditions \\
\hline & of cases $\left(\mathrm{PAR}=50-300 \mathrm{~mol}_{\text {photon }} \mathrm{m}^{-2} \mathrm{~s}^{-1}\right)$ & (standard light and/or natural light) \\
\hline & Standard laboratory light used in $70 \%$ of cases & used in $70 \%$ of cases \\
\hline & Other lighting equipment used in $17 \%$ of cases & \\
\hline Water & Less than $10^{\circ} \mathrm{C}$ in $9 \%$ of cases & Between $10^{\circ} \mathrm{C}$ and $30^{\circ} \mathrm{C}$ in $77 \%$ of \\
\hline \multirow[t]{3}{*}{ temperature } & Between 10 and $20^{\circ} \mathrm{C}$ in $54 \%$ of cases & cases \\
\hline & Over $20^{\circ} \mathrm{C}$ in $23 \%$ of cases & \\
\hline & Not monitored in $14 \%$ of cases & \\
\hline Conditions of & Rooted in the soil it grew in, in $52 \%$ of cases & Rooted in the soil it grew in, in $52 \%$ of \\
\hline vegetation used & Uprooted in $22 \%$ of cases & cases \\
\hline in a flume & Stems cut from plants in $26 \%$ of cases & \\
\hline
\end{tabular}


Table 2 Description of environmental conditions for each treatment (the characteristic factor of each treatment is underlined). Conductivity, and $\mathrm{pH}$ of water were measured daily, differences in concentration of anions between pond water and tap water is reported in the text. The parameter $\mathrm{z}$ stands for depth in the water column.

\begin{tabular}{|c|c|c|c|c|c|c|}
\hline \multirow[t]{2}{*}{ Treatment name } & \multirow[t]{2}{*}{$\begin{array}{l}\text { Type of } \\
\text { water }\end{array}$} & \multirow[t]{2}{*}{$\begin{array}{c}\text { Temperature } \\
\left({ }^{\circ} \mathrm{C}\right)\end{array}$} & \multicolumn{2}{|c|}{$\begin{array}{l}\text { Light irradiance } \\
\left(\mu \mathrm{mol}_{\text {photon }} \mathbf{m}^{-2} \mathbf{s}^{-1}\right)\end{array}$} & \multirow[t]{2}{*}{$\begin{array}{c}\text { Conductivity } \\
\qquad\left(\mu \mathrm{S} \mathrm{cm}^{-1}\right)\end{array}$} & \multirow[t]{2}{*}{ pH } \\
\hline & & & $\mathrm{z}=\mathbf{0} \mathrm{cm}$ & $z=24 \mathrm{~cm}$ & & \\
\hline Pond Water & Pond water & $16-22$ & $150 \pm 30$ & $50 \pm 5$ & $540-608$ & $8.5-8.71$ \\
\hline Tap Water & Tap water & $16-22$ & $150 \pm 30$ & $50 \pm 5$ & $632-674$ & $8.38-8.61$ \\
\hline Low Temperature & Pond water & $\underline{12-13}$ & $150 \pm 30$ & $50 \pm 5$ & $530-637$ & $8.55-8.74$ \\
\hline High Temperature & Pond water & $\underline{25-32}$ & $150 \pm 30$ & $50 \pm 5$ & $603-740$ & $8.6-8.68$ \\
\hline Low Irradiance & Pond water & $18-23$ & $\underline{2 \pm 1}$ & $\underline{0.5 \pm 0.1}$ & $611-681$ & $8.58-8.71$ \\
\hline High Irradiance & Pond water & $18-29$ & $350 \pm 25$ & $\underline{85 \pm 5}$ & $569-643$ & $8.55-8.78$ \\
\hline
\end{tabular}

Table 3 Results of one-way ANOVA (F statistic, p value, eta squared) and results of the Brown-Forsythe (BF) test on health status metrics for each species. Complete results of Tukey's HSD tests on health status data are reported in the supplementary material.

\begin{tabular}{lcclll}
\hline Species & Metric & $\begin{array}{l}\text { F statistic } \\
\text { (ANOVA) }\end{array}$ & $\begin{array}{l}\text { p- value } \\
\text { (ANOVA) }\end{array}$ & $\begin{array}{l}\boldsymbol{\eta}^{2} \\
\text { (ANOVA) }\end{array}$ & $\begin{array}{l}\text { p- value } \\
\text { (BF test) }\end{array}$ \\
\hline P. crispus & $F_{v} / \mathrm{F}_{\mathrm{m} 5}$ & $\mathrm{~F}_{3,31}=1.28$ & 0.30 & 0.121 & 0.84 \\
& $m_{F}$ & $\mathrm{~F}_{3,31}=3.42$ & 0.03 & 0.268 & 0.82 \\
\hline C. stagnalis & $F_{v} / \mathrm{F}_{\mathrm{m} 5}$ & $\mathrm{~F}_{5,47}=2.13$ & 0.08 & 0.202 & 0.29 \\
& $m_{F}$ & $\mathrm{~F}_{5,47}=1.10$ & 0.38 & 0.115 & 0.72 \\
\hline M. verticillatum & $F_{v} / \mathrm{F}_{\mathrm{m} 5}$ & $\mathrm{~F}_{5,47}=2.70$ & 0.03 & 0.244 & 0.67 \\
& $m_{F}$ & $\mathrm{~F}_{5,47}=5.31$ & $\ll<0.01$ & 0.387 & 0.01 \\
\hline
\end{tabular}


Table 4 Results of GLM analysis of $\boldsymbol{F}_{\boldsymbol{v}} / \boldsymbol{F}_{\boldsymbol{m} \mathbf{5}}$ and $\boldsymbol{m}_{\boldsymbol{F}}$ created using stepwise linear regression. Model of $\boldsymbol{F}_{\boldsymbol{v}} / \boldsymbol{F}_{\boldsymbol{m} \mathbf{5}}$ can be expressed as: $\boldsymbol{F}_{\boldsymbol{v}} / \boldsymbol{F}_{\boldsymbol{m} \mathbf{5}}=$ Intercept + Species + Treatment; model of $\boldsymbol{m}_{\boldsymbol{F}}$ can be expressed as $\boldsymbol{m}_{\boldsymbol{F}}=$ Intercept + Species $\times$ Treatment (interactions between factors are not shown).

\begin{tabular}{lcccccccc}
\hline & \multicolumn{7}{c}{$F_{v} / F_{m 5}, \mathrm{R}^{2}$ adj $=0.166$} & \multicolumn{7}{c}{$m_{F}, \mathrm{R}^{2}$ adj $=0.484$} \\
\hline & Estimate & St. error & $\mathbf{t}$ Stat & p-value & Estimate & St. error & t Stat & p-value \\
\hline Intercept & 0.764 & 0.009 & 81.326 & $\ll 0.01$ & -0.012 & 0.003 & -4.431 & $\ll 0.01$ \\
C. stagnalis & -0.022 & 0.009 & -2.539 & 0.012 & 0.001 & 0.004 & 0.258 & 0.797 \\
M. verticillatum & -0.034 & 0.009 & -3.936 & 0.0001 & 0.011 & 0.004 & 2.888 & 0.005 \\
Tap Water & -0.037 & 0.012 & -3.009 & 0.003 & 0.0003 & 0.004 & 0.075 & 0.940 \\
Low Temperature & -0.003 & 0.011 & -0.229 & 0.819 & -0.009 & 0.004 & -2.335 & 0.021 \\
High Temperature & -0.011 & 0.011 & -0.995 & 0.322 & 0.001 & 0.004 & 0.221 & 0.825 \\
Low Irradiance & 0.005 & 0.012 & 0.373 & 0.710 & 0.003 & 0.004 & 0.780 & 0.437 \\
High Irradiance & -0.007 & 0.011 & -0.630 & 0.530 & 0.001 & 0.004 & 0.309 & 0.758 \\
\hline
\end{tabular}

Table 5 Mean and standard deviation of biomechanical properties for plants not exposed to treatments (i.e. control group). Note that 'Pond Water' was used as control for $\boldsymbol{E}_{\boldsymbol{t}}, \boldsymbol{E}_{\boldsymbol{b}}$ and $\boldsymbol{E}_{\boldsymbol{b}} \boldsymbol{I}$ of $C$. stagnalis because of a data bias in the control group. The unit of measurement of flexural rigidity is $\mathrm{Nm}^{2}$. Further note that mass density is reported only once for each species because it was measured using whole plants (i.e. not separating top and bottom parts of stems).

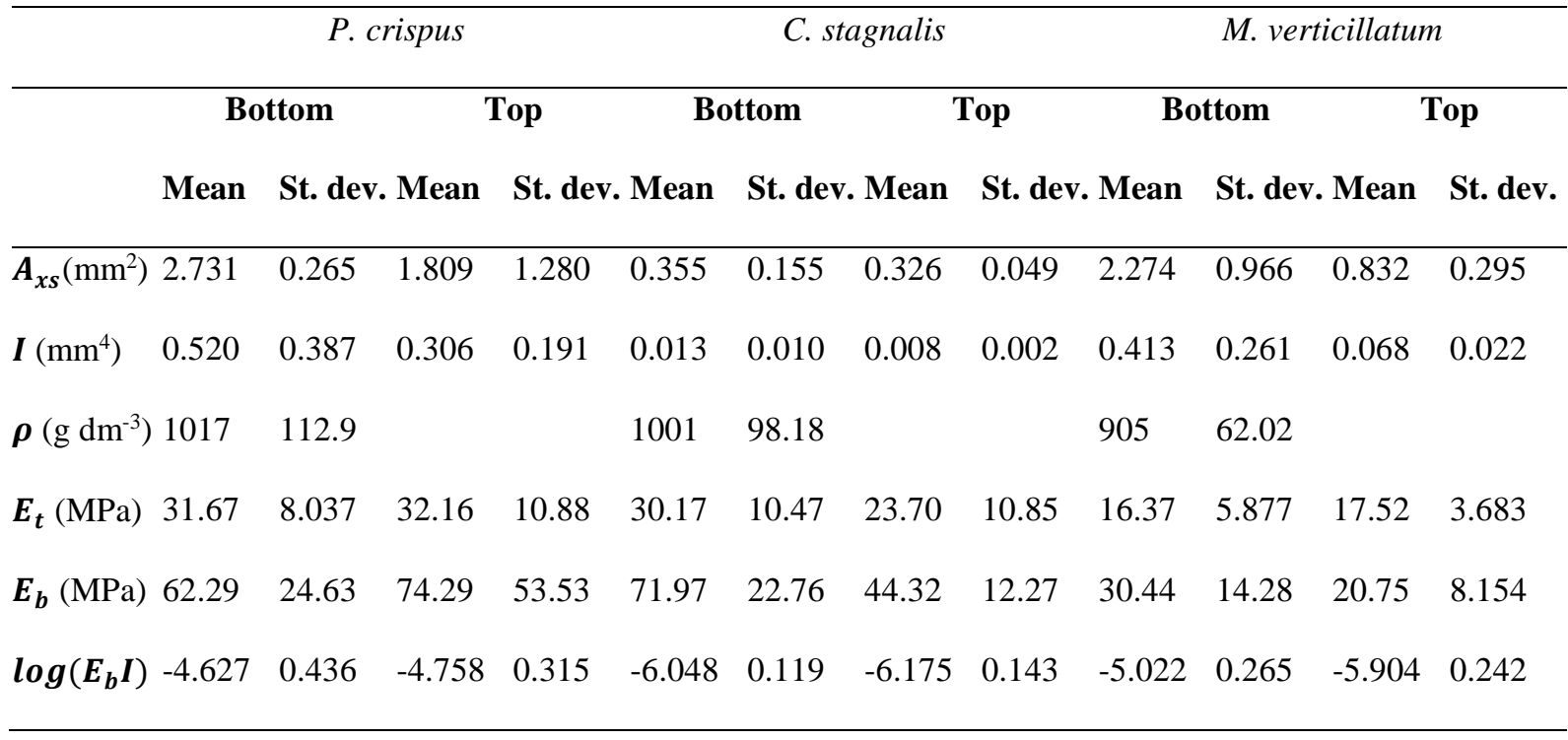


Table 6 Results of one-way ANOVA and multiple pairwise comparison tests of biomechanical properties. Each treatment was compared with the relevant control group; note that for C. stagnalis 'Pond Water' was used as control group. Only cases with $\mathrm{p}<0.017, \eta^{2}>$ 0.2 and $\mid$ variation $\mid>20 \%$ are shown. Significance level for $\alpha=0.1$ is equal to $p=0.017$, calculated using per-comparison error rate to account for multiple non-independent tests. Treatments are listed using their initials (e.g. T. W. for Tap Water).

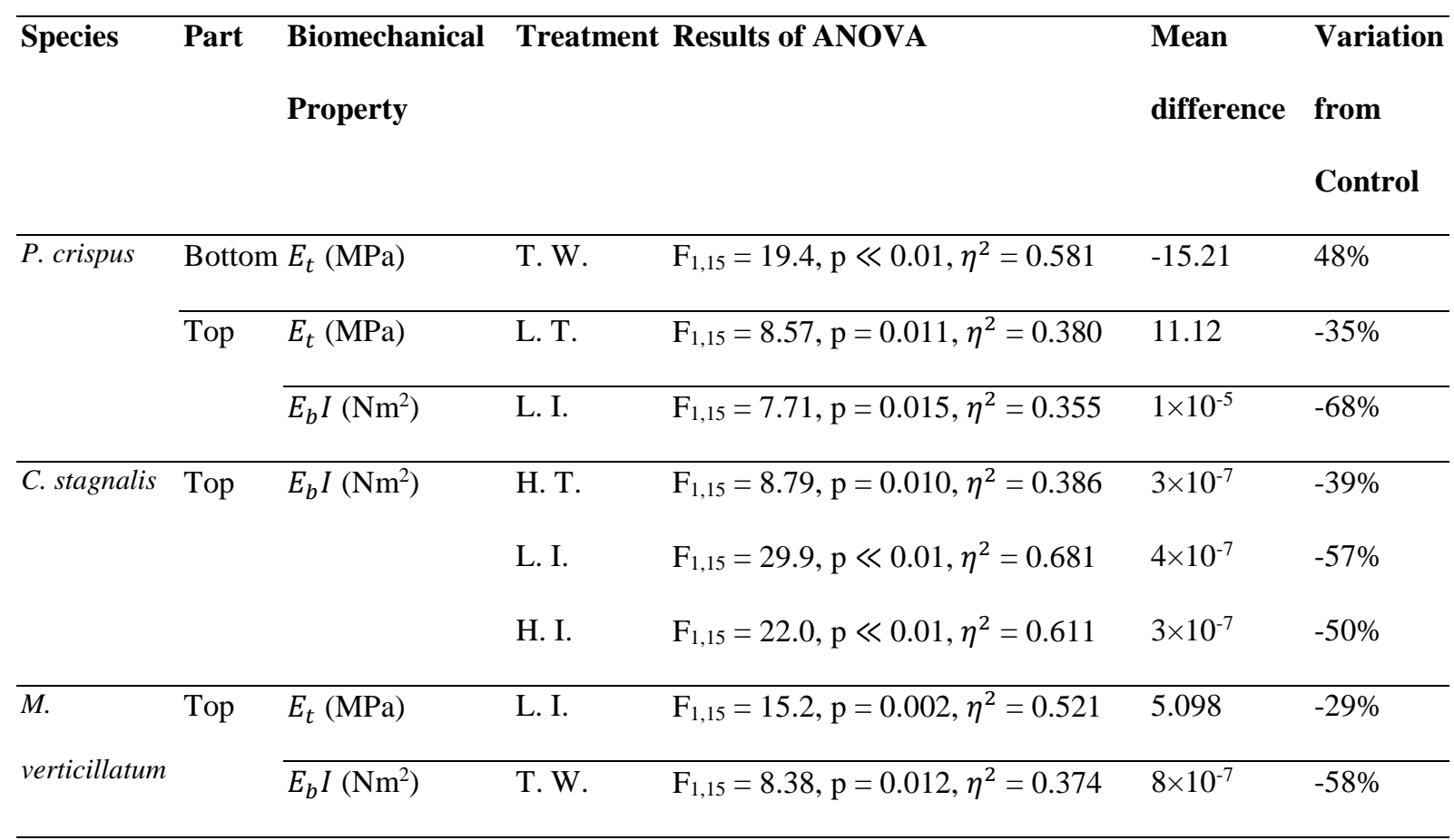


Table 7 Results of GLM analysis of $\boldsymbol{E}_{\boldsymbol{t}}$ and $\boldsymbol{E}_{\boldsymbol{b}} \boldsymbol{I}$.

\begin{tabular}{|c|c|c|c|c|c|c|c|c|}
\hline & \multicolumn{4}{|c|}{$1 / E_{t}, \mathrm{R}_{\text {adj }}^{2}=0.556$} & \multicolumn{4}{|c|}{$\log _{10}\left(E_{b} I\right), \mathrm{R}_{\text {adj }}^{2}=0.800$} \\
\hline & $\overline{\text { Estimate }}$ & St. error & t Stat & $\mathbf{p}$ & Estimate & St. error & t Stat & $\mathbf{p}$ \\
\hline Intercept & 0.026 & 0.002 & 12.67 & $\ll 0.01$ & -4.544 & 0.067 & -68.11 & $\ll 0.01$ \\
\hline C. stagnalis & 0.005 & 0.002 & 2.460 & 0.015 & -1.434 & 0.067 & -21.26 & $\ll 0.01$ \\
\hline M. Verticillatum & 0.043 & 0.003 & 13.01 & $\ll 0.01$ & -0.303 & 0.067 & -4.511 & $\ll 0.01$ \\
\hline Tap water & -0.004 & 0.002 & -1.659 & 0.099 & -0.081 & 0.069 & -1.174 & 0.241 \\
\hline Low temperature & 0.005 & 0.003 & 1.747 & 0.082 & -0.007 & 0.068 & -0.097 & 0.923 \\
\hline High temperature & 0.002 & 0.003 & 0.968 & 0.334 & -0.065 & 0.068 & -0.951 & 0.343 \\
\hline Low irradiance & 0.001 & 0.003 & 0.218 & 0.827 & -0.144 & 0.068 & -2.115 & 0.035 \\
\hline High irradiance & 0.003 & 0.003 & 1.318 & 0.189 & -0.121 & 0.069 & -1.763 & 0.079 \\
\hline Top part & 0.008 & 0.002 & 3.935 & $\ll 0.01$ & -0.593 & 0.068 & -8.744 & $\ll 0.01$ \\
\hline C. stagnalis - top & 0.008 & 0.003 & 2.335 & 0.020 & 0.254 & 0.096 & 2.640 & 0.009 \\
\hline M. verticillatum - top & -0.016 & 0.005 & -3.336 & 0.001 & -0.484 & 0.095 & -5.074 & $\ll 0.01$ \\
\hline
\end{tabular}

Table 8 Results of GLM analysis of $\boldsymbol{E}_{\boldsymbol{t}}$ and $\boldsymbol{E}_{\boldsymbol{b}} \boldsymbol{I}$ and the maximum quantum yield of photosystem II

\begin{tabular}{lllllllll}
\hline & \multicolumn{7}{c}{$1 / E_{t}, \mathrm{R}^{2}$ adj $=0.568$} & \multicolumn{7}{c}{$\log _{10}\left(E_{b} I\right), \mathrm{R}^{2}{ }_{\mathrm{adj}}=0.811$} \\
& \multicolumn{1}{l}{ Estimate } & St. error & $\mathbf{t}$ Stat & $\mathbf{p}$ & Estimate & St. error & $\mathbf{t}$ Stat & $\mathbf{p}$ \\
\hline Intercept & -0.049 & 0.042 & -1.159 & 0.248 & -5.584 & 0.395 & -14.118 & $\ll 0.01$ \\
C. stagnalis & 0.160 & 0.060 & 2.666 & 0.008 & -1.422 & 0.074 & -19.201 & $\ll 0.01$ \\
M. verticillatum & 0.069 & 0.049 & 1.414 & 0.159 & -0.271 & 0.074 & -3.676 & $\ll 0.01$ \\
Top & 0.011 & 0.004 & 2.762 & 0.006 & -0.625 & 0.077 & -8.106 & $\ll 0.01$ \\
$F_{v} / F_{\text {m5 }}$ & 0.103 & 0.056 & 1.851 & 0.066 & 1.303 & 0.517 & 2.518 & 0.012 \\
C. stagnalis - Top & 0.007 & 0.005 & 1.328 & 0.186 & 0.264 & 0.103 & 2.561 & 0.011 \\
M. verticillatum - Top & -0.023 & 0.005 & -4.434 & $\ll 0.01$ & -0.458 & 0.101 & -4.546 & $\ll 0.01$ \\
\hline
\end{tabular}



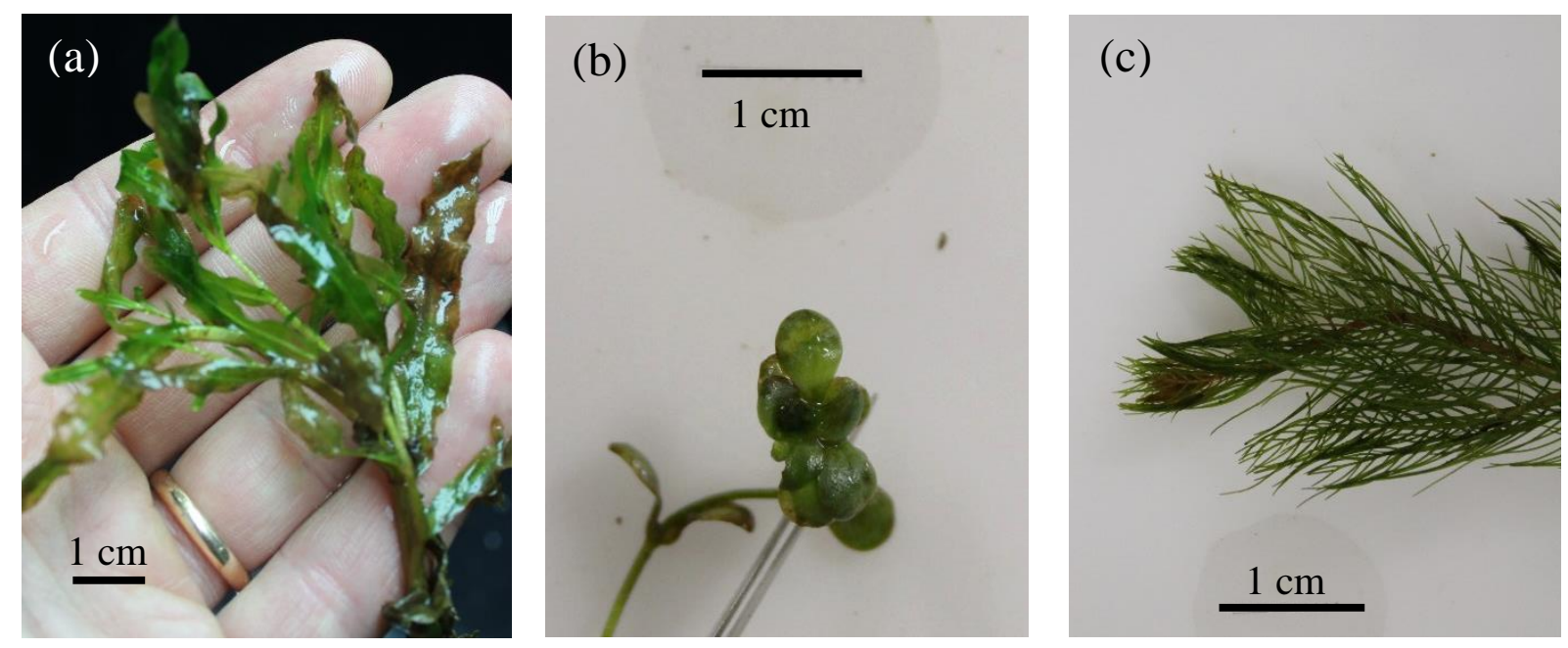

Fig. 1 Different morphological traits shown by leaves: (a) P. crispus have oblong linear leaves a few cm long; (b) C. stagnalis top leaves are compounded, spoon-shaped and grouped in rosettes; (c) M. verticillatum leaves are compounded with multiple needle-like leaflets.
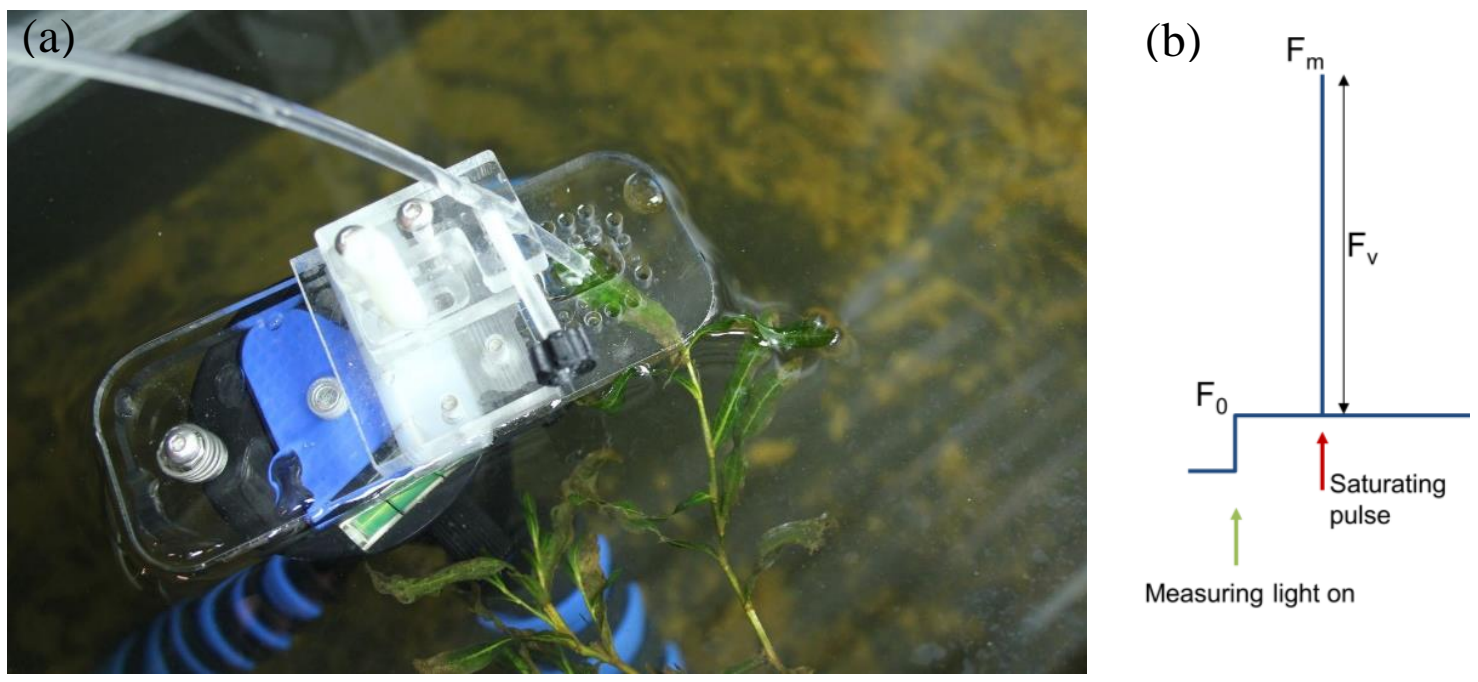

Fig. 2 (a) Details of a chlorophyll fluorometer: light pipe extension, leaf clip, and sampled leaf; (b) idealized chlorophyll fluorescence signal of a $\boldsymbol{F}_{\boldsymbol{v}} / \boldsymbol{F}_{\boldsymbol{m}}$ test on a dark-adapted sample. 
(a)

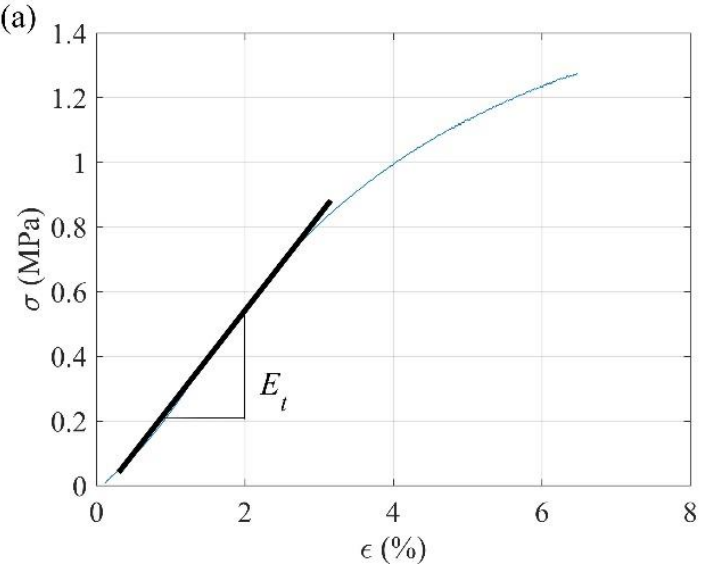

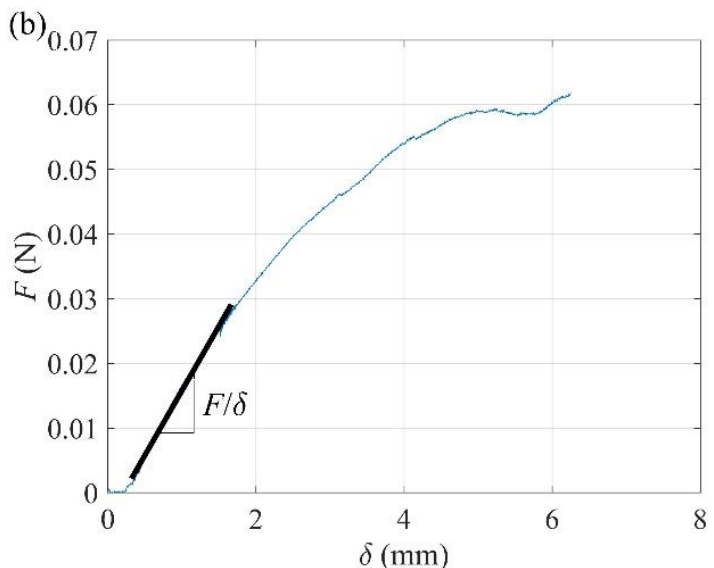

Fig. 3 Example of (a) stress-strain curve from uniaxial tensile tests and (b) forcedisplacement curve from 3-point flexural tests conducted on samples of $P$. crispus exposed to 'Pond Water' treatment.

(a)
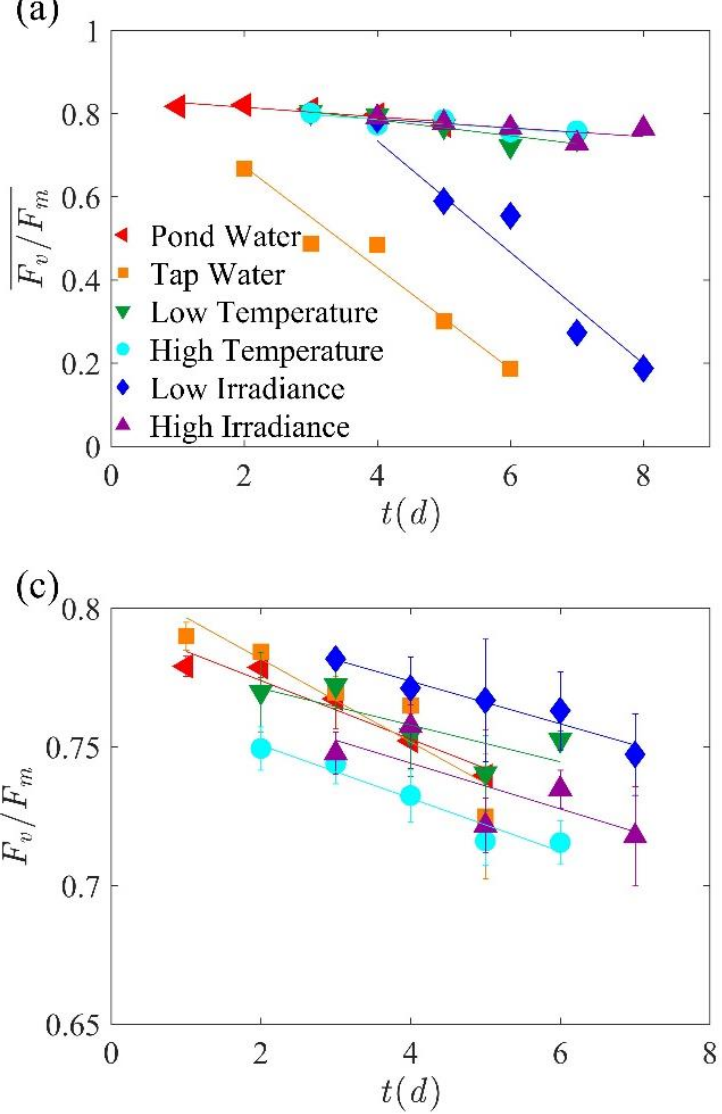

(b)

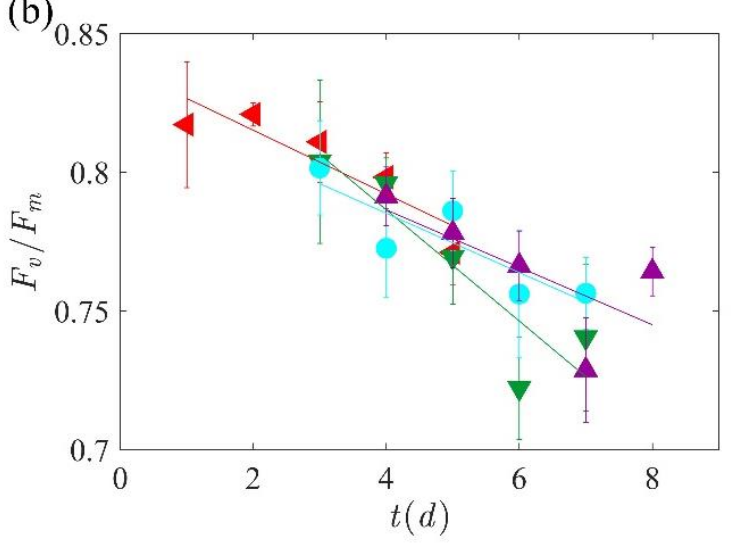

(d)

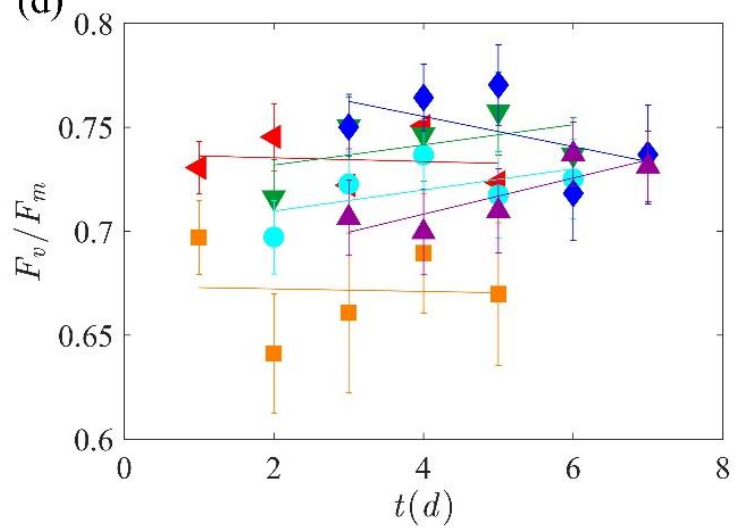

Fig. 4 (a) Mean daily values of $\boldsymbol{F}_{\boldsymbol{v}} / \mathbf{F}_{\boldsymbol{m}}$ for $P$. crispus, markers represent mean daily values across all plants in a treatment, a linear regression for each treatment was calculated. In (b-d) 
a linear regression of $\boldsymbol{F}_{v} / \mathbf{F}_{\boldsymbol{m}}$ for each plant was obtained and the line calculated with the mean value of intercepts and slopes within each treatment is shown (markers represent mean values of $\boldsymbol{F}_{v} / \mathbf{F}_{\boldsymbol{m}}$, bars are the standard deviations of $\boldsymbol{F}_{\boldsymbol{v}} / \mathbf{F}_{\boldsymbol{m}}$ in each day) for (b) P. crispus, (c) C. stagnalis and (d) M. verticillatum. Note that the scale is different in each figure and (b) does not show results for the 'Tap Water' and the 'Low Irradiance' treatments because valid data are insufficient to compute linear regressions. 